\title{
The Concept of Tricycle as an Artistic Point of View in Creative Art
}

\author{
Ananta Hari Noorsasetya* \\ Department of Product Design \\ The Faculty of Design and Creative Arts \\ Mercu Buana University, Jakarta, Indonesia.
}

\author{
Prayanto Widyo Harsanto* \\ Graduate School of Indonesia Institute of the Art \\ Indonesia Institute of the Arts \\ Yogyakarta, Indonesia
}

\begin{abstract}
This article is more focused on processing visual bicycle forms that are not common, the perspective on the values of creativity is important in creating works of art. The basic idea of shifting the point of view of the science of new media such as used objects or any objects obtained around our lives is the main artistic concept in the process and results of the creation of three-wheeled works of art. The process becomes very important, processing and producing a form of bicycle creation is not commonly used, but rather its artistic value. The bicycle language and function value are spelled out, the rule as a used object in general is deformed into a new non-conventional form. The renewal that results from expression and exploration forms the characteristics of tricycles to be of many varieties and has the value of creative arts and artistic value.
\end{abstract}

Keywords--Tricycle Bike; Art; Artistic; Three Wheeler

\section{INTRODUCTION}

What would your reaction be if someone ask you, do you ever a have a tricycle? The answer inevitable varies from one person to the other. It takes some courage and strife to go back in the memory of one's past. The joyous moment of the whole family. The sublime feelings of parents witnessing their child is ecstasy, circling the room on the first trial. This incidence happens on and on through generations. It has become our perpetual practice. It has become our culture. A culture transformed by a technical invention. It was Mr. Karl Drais who had invented velocipede the forerunner of what we call nowadays as bike which had changed human culture in regards of their mobility and mode of transportation. Many people had circled the globe on bike and as story goes that the Vietminh had won the war thanks to good logistics supply carried on bicycles.

Aside from its functional aspect either the bike or tricycle have gone through enormous modification, namely their ergonomics and esthetics which both are, we could say the artistic side or the domain of artistic expression. In childhood, tricycles became one of the games that are generally owned by children under the age of 6 years. In the memory of the author, the tricycle has become a tool for interaction of excitement, jesting, laughing freely, so that it enters the author's dream world where the portrait of the childhood is repeated over and over. Similarly, the memory is quite sad experienced by the author, where the tricycle at that time was very difficult to obtain so clearly recorded by the author how jealousy bursts when friends play with their own tricycles. Bicycles are a

\footnotetext{
* Corresponding authors: Ananta Hari Noorsasetya, Department of Product Design, The Faculty of Design and Creative Arts, Mercu Buana University, Jakarta, Indonesia, email: anantastya@yahoo.com, and Prayanto Widyo Harsanto, Graduate School of Indonesia Institute of the Art, Indonesia Institute of the Arts, Yogyakarta, Indonesia, email: prayantowah@ymail.com
}

place for deep sensation of experience, and have become a shadow of the past that is important enough to be explained.

Bicycles have become life portraits, childhood portraits lost with bicycles that the author wants. Through bicycles it can be illustrated how to accept the peer teasing remembers because they do not have a bicycle, the sound of a loud bell is heard, the faint language of sound that occurs due to friction between iron and iron is heard in the memory of how cranks or pedals like heavy need power to pedal, in contrast to bicycles today in general that are so light. Anger and the inability to ask for and buy a bicycle immediately made it the main reason, but when getting a bicycle that was desired, even peers at that time had switched to a type of game like video games.

The author's childhood experience leads to a situation where the author has strong stimulation with a bicycle tricycle. According to Jean-Jacques Rousseau, in Children and Their Art Method for Elementary School, Al Hurwitz and Michael Day, USA, an 18th-century philosopher whose ideas were strongly influenced by his childhood education reinforced the idea that art is inseparable from interest in childhood, the child's environment when raised, exploration of form and material manipulation, so forming psychological perceptions. This condition is also, if associated with Gestalt thinking, it is clearly illustrated that the author has a unique visual perception of the tricycle through the organization of sensation components that have relationships, patterns, or associations as a whole. As a learner in his childhood, the author has acquired a knowledge and then after being associated with various types of aspects in a learning situation, the writer gets a new understanding and point of view (insights).

\section{SOCIAL ASPECT}

In relation to social conditions and the development of the times, there is one fact that is evidence that shows the social situation of historical figures, whether the perpetrators or witnesses are located, such as the atmosphere of the era, environment, and society. A historical event that is influenced by social problems that occur in the community's living environment, such as problems experienced by the author himself. Social problems that arise and develop in society often cause an event. Users of products labeled "hobbies" have a long history, such as the desire to do or get things quickly. This is in sharp contrast to what was written by historians or previous thinkers by looking at the previous environment, 
namely how the regional structure is still very limited and not many people have interests, but a few people try to create and continue to develop tools fulfillment of the needs in this case of bicycles, and this historical event influenced by individual interests how to create fast auto and enter the joints of the user community, giving rise to an important event in shaping humanity increasingly dependent on the results of his creation at that time. The shift is increasingly apparent in the following decades, namely the development of products as a consumption value that is very important at that time, so that it becomes a role that can be picked by many users. As with bicycles, the object was a tool for how everything became fulfilled, namely the problem of time, distance, simple or trying to draw simplicity in a form that was very complicated, aesthetically pleasing, until one moment the process disappeared as everything changed, the bike wasn't again it becomes a tool for fulfilling every day's needs, but changing functions becomes a tool of dialogue in certain events, for example interacting with each other with different groups, becoming the media for the competition business, a trend that enters the social strata in its embrace. This symptom raises many competitors with all their interests, starting from the shift of product discourse to the current style of discourse that the community has. From time to time humans see from different viewpoints so that the perspective on the media is no longer just ordinary but has more to the value of the function it wants, moreover the social changes in urban society in relay continue to cause many new symptoms or even though creating a new trend from city to village, this journey enters through the history of how daily records make the phenomenon of the tool change function.

The creation of the tricycle by the author is also a response to existing social conditions, where in the end, human needs as individuals who are unique, as well as shifting perspectives, penetrating past and present space boundaries, are important to present. Strengths from the artistic side, functional values, and psychological understanding are the basic strengths of this tricycle work, as well as its relevance to social science, so this work is intended to build visual images that can bridge abstract and concrete thinking at the same time. A picture acoording to Harnad, Handbook of the Arts in Qualitative Research, Gary, J Knowles, Andra L. Cole, Shaun McNiff, remind us, may not only be a thousand words, but it is also almost almost instantaneously at a glance, whereas those thousand words require to listen or to read.

\section{ARTISTIC CONCEPT}

\section{A. The Tricycle Concept}

Artwork is the expression of imagination utilizing various medias, tied to background and memories of the past. It is because of this reason the writer tries to express the childhood memory, "The Tricycle" concept as the frame of the artwork.

It cannot be denied that this tricycle has contributed so much in a child's development, physically and mentally. Motoric, coordination of brain and muscles. Turn right, turn left, reverse and keeping balance as not to overturn. Building fantasy and imagination to cross continents and lofty mountains and brag that this tricyclette has wings. All these which is considered as crazy idea constantly flash in the mind and embedded as an obsession to express three wheelers as medium of art expression. The concept is to use industrial waste such as discarded steel bars and pipes, sheet and wood as well rubber as an interface material such as wheels, tires and saddle.

These materials can be modified by printing or made new with raw steel material. Pipes connecting each material are made using the necessary artificial tools. Pipes can be bent as needed according to the design flow or work chart that is already available. Steel plate cut into pieces as needed, to eliminate some parts that still have the form of a tricycle design in general. Tricycle bikes are thoroughly scrutinized so that there are parts that can be distorted and packaged in the form of deformation. Reference: Richard Hallet, the Deconstructed Bike. A grand Tour of the Road Bicycle. Hatchette, UK. Frame, saddle, handlebars, fork, pedal, brake, wheel, seat, fender, standard to the part of the lamp. Another part is the type of pipe with a certain diameter that is used for the frame is also examined with elements of weight and strength, because each material used contains what is called this load because as a parameter the bicycle produced will be used as artwork or use only. Because the work that is produced is more towards the fine art genre, the burden will be more flexible because the bicycle he created visualizes the presence of observations of artistic experience and more aesthetic elements and includes the benefits.

The concept of a tricycle remains the main reference, but the parts that really need to be changed thoroughly are welcomed. The concept of wood waste material that is found is used to adjust form requirements. Wood can also be an artistic exploration accent, make a backrest, and make a seat for legs or parts needed. Rubber is needed to support iron material, closing sharp edges. The wheels function for the drive, generally can rotate, but here the front wheels are connected with the handlebar only in the designation turning right and left, other functions such as brakes are no longer used. The pedals for pedaling were no longer used, even eliminated. The use functions on a bicycle are really deformed on a large scale. This concept is used to eliminate some parts so that new ideas emerge. The result is a tricycle as the main character reference to build a new creation that is quite crazy. This madness is the result of developing concepts in the field of bicycle creation and can be studied, in order to be able to translate them into applied and non-applied research to answer the challenges of complex competition in the art industry in the future. The concept is able to analyze, plan and design a Visual work that can communicate messages effectively how bicycles are seen not as a whole, aesthetically, artistically and strategically through creative, analytical and innovative ways.

The concept of a tricycle that is identical to children has been modified for its use. This part of the concept is also based on mastering various bicycle rereading techniques through different languages, methods used, hardware, software and technology-based tools in the field of creative arts. sensitivity and responsiveness to current cultural situations and conditions also form the basis of other social attitudes and behaviors that develop in society. Passion and passion for 
work and the ability to think about turning bicycle products into artistic bicycle art. The concept also cannot be separated from working independently or working in a work team.

\section{B. Creation Method}

Method is to say the way it is done or how the process is laid down to achieve the aim. The first step is Saturation. Collecting all pertaining information through literatures, medias and museum. The second step is incubation. At this period all the information gathered is settled in the mind and imagination or fantasy is formed to become a new entity or a new creation having a new character different from all the visuals and information collected previously. Then come the pre creation period. It is the period when the study of the material chosen to use in expression of the aim. In this case since discarded metal is going to be used so basic skill of welding metal, bending and cutting is pursued.

Lastly as the consequence of choosing a three wheeler concept so all the essentials or the embedded philosophy is drugged to form the conditions of creation.

The creation of the three steps above is, collecting all the data to be rewritten, aspects of philosophy will be applied to the design of the shape and process until finished. Creativity refers to the concept that has been designed.

Art criticism according to M Dwi Marianto, Art \& Life Force, in a Quantum Perspective. Scritto Books Publisher, Yogyakarta. The art world and the caritas use their intellectual concepts to be seen and deepened using categories of objects and objects and their frameworks, frameworks as process and concept charts, creativity formed by existing sources. The process of art criticism is done as an enrichment of elements into the presentation presented by the author, criticism as assessing the work produced because bicycle construction is the main visual aspect of the frame, how the frame is not finished so that it may be continued as a distorted object, how will there be figures produced into the values it contains. The work can be presented into aspects of visual performance, one of which is a movable three-dimensional work because the wheel elements still function. This aspect was studied in the development of art today, the correlation of the results of tricycle creation was linked to how the history of art in Indonesia today has become the most important part of the world, a manifesto, also how this work produces art that carries the history of art with new media.

\section{Art Based Research}

According to Shaun McNiff, Handbook of the Arts in Qualitative Research ,Gary, J Knowles, Andra L. Cole, Shaun McNiff: Perspectives, methodologies, examples, and issues, research based on art, is a process characterized by figures or objects, where the objects themselves are then observed, studied and in the end these observations give rise to new understandings. In the case of the author, the presence of a tricycle as an objects is so important to be revealed, especially that a tricycle is a benchmark and a new perspective on work.
Tricycles through the process of thinking and making ultimately produce new creative theories and concepts.

In practice-based research, there are some interesting things that can be found through a variety of careful observations. One of them is how this practice-based research can bring a new cultural insight and knowledge that can be empirically proven, compared to only a speculative discourse. The new knowledge and insights can instill new understanding of several things in the broader spectrum, as well as how the experience of audience involvement, the strategy for making a system so that art can be able to involve many people, taxonomy and collaborative models, as well as the artwork itself ; composition, installation, performance and exhibition.

The artwork plays a central role in the process, and it is hoped that the results can be shared within a wider range of communities, so that the message that the artist wishes to express can be conveyed well. How a work of art can offer a new perspective that is able to bring its audience to a new, broader, and multifaceted understanding. Then this practicebased research is very fundamentally needed to bring changes to the history of art. With this, the development of exploratory discourse on issues and debates in the history of art itself becomes possible. In today's development, we face an era where the historical range is as wide as it is, no longer has a methodology or explanatory model, even new art is a combination of several disciplines.

Creative arts in the context of education, here is the taking of experiments by taking a design concept. The method offered is how to make one form of tricycle freely deformed to produce artistic work. Designs that are made in groups are then broken down into a research process. The method and theoretical importance are applied to work drawings as the initial idea for exploration to be a manifestation of art. Students then combine ideas and theories that are discussed together and build a new method and then present them to their work groups. The aim of all that is done by these students is to bring new ideas and create new media art into knowledge in the realm of education. Through a long process and experimenting the goal is to build research based on research through the journey of the artistic process. Art-based research methods here are the creation of works of art that apply to the manufacture of art products of the type of tricycle or can be used with any art. These fundamentals are then focused on starting to look for, study, record lots of references from the materials needed to realize artistic articulated tricycles. The output of this research obtained is that tricycle is part of building the main learning and research interactions in creating the artwork.

Reference: Handbook of the Arts in Qualitative Research, Gary, J Knowles, Andra L. Cole, Shaun McNiff, in the research process itself, data that becomes the focus of information search will emerge as a reaction from the existence of images or objects as memory burst lighters so that it will become the basic structure for further research. For example, if the work of Tricycle by this author is used by several ethnic groups, then each different reaction will arise and can be recorded as input of new data. As in an exhibition, 
comments from the audience will be very important to bring up new data to be examined and discussed further in a structured interview. By presenting an image or object to be discussed, the various reactions and comments that appear there will be contained in various kinds of emotions, feelings, thoughts, and all other forms of information. Even everything that is sometimes a taboo to be lifted, then this image or art object can uncover the other side of someone, an event, which might be too painful or too embarrassing to reveal. In fact, the image or object of art will be able to change one's perspective, while at the same time inspiring and making new data and information for object lovers themselves. This work will be a communication medium that can bridge past memories, including the culture that shapes, socio-economic background, psychological aspects, and so on.

\section{The RESUlt OF THE CREATION}

The joy and satisfaction experience gained through working in art had, therefore converted the feeling to become as "not an outsider" in the realm of visual theory which is an important discourse. An issue of interest is the development of bicycle. It is the technological side which is worth to be mentioned, such as the aspect of movement mechanism, its functional aspect but without artistically touch the product would become dull and barren. Nevertheless should the art side visualization be too exaggerated then it could bolster the border of structural discourse. The writer has a strong desire which triggers imagination or visualization so tactile as if it is real and has happened leaving the functional as well the various technological forms. Disobeying the well recorded and it's harmony with art or the esthetical aspect of the development of bicycle. These changes be they technical or esthetics in fact is the reflection of the desire for greater authority or power of the artist in the strife to win in the market competition. To express their creativity and expansion of their extra ordinary insight. Some of the works for the ordinary view may look as an exaggeration leaving out the functional components. Such as substituting the main frame with a cylindrical shape out of discarded metal pipe or container. There are of course unlimited ways to express the artistically mind of the creator depending on the limitation of the surroundings. For illustration here are some pictures the writer has express himself relating the childhood memory being attached to the tricycle.

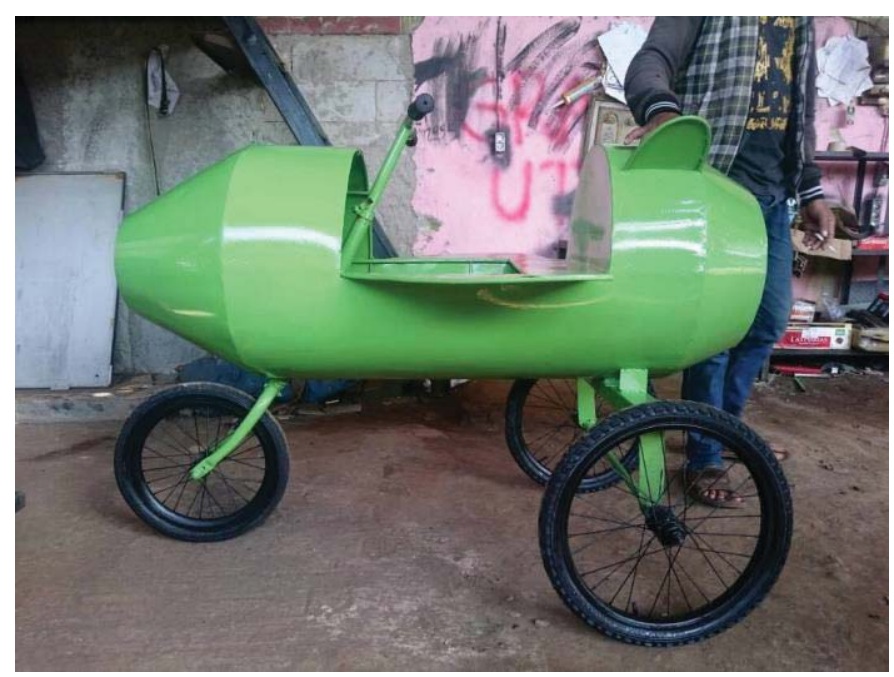

Fig. 1. Sideways of the tricycle. The work made in the form of a tricycle that has been finished $80 \%$. Materials made from used Drum Oil, Used Steel Plate and Bicycle Wheels.

\section{REFERENCES}

[1] S.P. Soedarso, "Trilogi Seni", Penciptaan dan Eksistensi dan Kegunaan Seni, BP ISI Yogyakarta, 2006.

[2] S. Bastomi. "Wawasan Seni," IKIP Semarang Press, Semarang, 1990, pp.109-110.

[3] Marianto, M. Dwi, Art \& Life Force, in a Quantum Perspective. Scritto Books Publisher, Yogyakarta, 2017, p. 271.

[4] A. Hurwitz, and D. Michael, "Children and Their Art: Methods for the Elementary School," $8^{\text {th }}$ ed., Thomson: Wadsworth, USA, 2007,p.6.

[5] J.K. Gary, C.L. Andra, M. Shaun, "Handbook of the Arts in Qualitative Research,” Sagr Publications, Inc., Canada, 2008, pp.44-48.

[6] R. Halllet, "The Bike Deconstructed. A grand Tour of the Road Bicycle," Hatchette, UK, 2014 p.184. 